\title{
"Our World Is Shaking Because of Corona": Intersecting Crises and Disrupted Life Transitions among Young People in Ethiopia and Jordan Pre- and Post-COVID-19
}

\author{
Nicola Jones ${ }^{1}$, Kate Pincock ${ }^{1, *}$, Sarah Alheiwidi ${ }^{2,3}$ and Workneh Yadete ${ }^{4,5}$ \\ 1 Gender and Adolescence: Global Evidence (GAGE), London SE1 8NJ, UK; n.jones@odi.org.uk \\ Refugee Studies Centre, University of Oxford, Oxford OX1 2JD, UK; Sarahalheiwidi97@outlook.com \\ Gender and Adolescence: Global Evidence (GAGE), Amman, Jordan \\ 4 Gender and Adolescence: Global Evidence (GAGE), Addis Ababa, Ethiopia; worknehyadete@gmail.com \\ 5 Quest Research, Training and Consultancy PLC, Addis Ababa, Ethiopia \\ * Correspondence: k.pincock.gage@odi.org.uk
}

check for

updates

Citation: Jones, Nicola, Kate Pincock, Sarah Alheiwidi, and Workneh

Yadete. 2021. “Our World Is Shaking

Because of Corona": Intersecting

Crises and Disrupted Life Transitions among Young People in Ethiopia and Jordan Pre- and Post-COVID-19. Social Sciences 10: 470. https:// doi.org/10.3390/socsci10120470

Academic Editor: Carlos Teixeira

Received: 30 April 2021

Accepted: 17 November 2021

Published: 7 December 2021

Publisher's Note: MDPI stays neutral with regard to jurisdictional claims in published maps and institutional affiliations.

Copyright: (c) 2021 by the authors. Licensee MDPI, Basel, Switzerland. This article is an open access article distributed under the terms and conditions of the Creative Commons Attribution (CC BY) license (https:// creativecommons.org/licenses/by/ $4.0 /)$.

\begin{abstract}
Our article explores how intersecting crises, sociocultural norms around gender, age, household and community and broader political and economic shifts are affecting youth transitions. We draw on qualitative virtual research with 138 young people in Ethiopia and Jordan undertaken between April and August 2020. COVID-19 is exacerbating ongoing crises and gender inequalities in Ethiopia and Jordan and foreclosing opportunities for youth transitions. In Ethiopia, the pandemic has compounded the precarity of young people who have migrated from rural to urban areas, often to locations where they are socially marginalised. In Jordan, the confinement of young people affected by forced displacement to their households with extended family during pandemic-related service closures augments existing perceptions of an extended 'waithood' - both psychosocially and economically. In both contexts, conservative gender norms further entrench the restrictions on adolescent girls' mobility with consequences for their opportunities and wellbeing. This article makes an important contribution to the literature on gender, migrant youth and the ongoing effects of the COVID-19 pandemic by showing how multiple crises have sharpened the social and political (im)mobilities that already shaped young men and women's lives in Ethiopia and Jordan and the consequences for their trajectories to adulthood.
\end{abstract}

Keywords: waithood; transitions; mobility; crisis; youth; gender; pandemic; refugee; migrant; LMIC

\section{Introduction}

In many low- and middle-income countries (LMICs), the socioeconomic crisis associated with the novel coronavirus COVID-19 has exacerbated many of the challenges facing mobile populations. Research and policy have begun to draw attention to the gendered impact of these intersecting crises, but there has been little attention to how crises have exacerbated vulnerabilities among groups of young people for whom mobility has previously generated opportunities to expand capabilities.

This article thus explores how young people are being affected by multi-layered crises induced by the global pandemic, as well as displacement and migration for work. Our empirical research is situated explicitly around the three key themes of this special issue of crisis, (im)mobilities and young life trajectories. Our study responded to the COVID-19 pandemic, drawing on qualitative virtual research with young people in Ethiopia and Jordan undertaken between April and August 2020. This work is nested within a broader longitudinal mixed-method study of gender and adolescence across LMICs affected by humanitarian and political crises, which have resulted in mass displacement, both within and across borders.

The trajectories of young people in Ethiopia and Jordan provide contrasting accounts of family and community dynamics and their consequences for adolescents in different 
contexts. In Ethiopia, the pandemic intersects with (im)mobilities associated both with the movement of young people for work and, more recently, internal displacement due to political upheaval; in Jordan, the pandemic intersects with mass forced migration into Jordan due to the crisis in Syria.

Mobility and immobility are not binary terms; the logic of each exists in the other (Nimfuhr and Sesay 2019). In recognition of this interdependence, we use the concept of '(im)mobilities' to highlight disjunctures between young, displaced people's experiences of, on the one hand, being defined by the state in relation to their status as inherently 'out of place' and, on the other, of being subject to restrictions on their movement associated with government responses to COVID-19.

These tensions are further shaped by sociocultural norms around gender, age, household and family and broader political and economic dynamics that shape young life trajectories. Specifically, we observe in this article how these dynamics have affected young people's transitions to adulthood, creating instead a prolonged period of 'waithood' (Honwana 2019). The concept of 'waithood' has been used to explore how young people are affected by but also respond to the constraints on traditional opportunities and routes into adulthood that have resulted from the changing nature of work under global capitalism. We use the term here to recognise the agency of young people and adolescents in navigating multiple shifting challenges while also underscoring the urgency of states and other actors to deliver support that reflects these realities.

\subsection{Context: Ethiopia}

The COVID-19 pandemic arrived in Ethiopia in March 2020 amid growing political tensions and hostilities and high rates of youth unemployment. The Government of Ethiopia has stated its ambitions for the country to reach middle-income status by 2025 (Kushkush 2015). The current generation of Ethiopian youth are the first to have been widely educated, with primary enrolment rates increasing dramatically from $21 \%$ to $93 \%$ between 1994 and 2014 (United Nations (UN) (2014)) and secondary school rates from $10 \%$ to $35 \%$ over the same period (United Nations Education, Scientific and Culture Office (UNESCO) (2021)). Simultaneously, Ethiopians' aspirations have shifted away from rural livelihoods and towards urban professionalism, leading to growing urbanisation (Camfield 2011; Schewel and Fransen 2018). Yet despite shifting aspirations-at both the state and individual levels - and increasing rural-urban mobility for work, more than half of young Ethiopians are unemployed (Wellbeing and Illbeing Dynamics in Ethiopia (WIDE) (2016)). In urban areas, young people are largely employed in the informal economy and are also chronically underemployed. At the last count in 2014, there were over 1.2 million ruralurban migrants living in Addis Ababa alone, and the majority were young and female (Central Statistical Agency 2014) ${ }^{1}$.

Unemployed young people must move around, continually seeking ways to make ends meet (Di Nunzio and Mihret 2015). However, the types of work available are largely undesirable as well as being poorly remunerated and insecure, especially for those who are educated, who perceived that this would expand their opportunities and elevate their status (Mains 2015). Research in Ethiopia by Young Lives found that adolescents who were enrolled in school or who had attained higher levels of education were more likely to aspire to migrate for work and were more likely to envisage undertaking further education (Schewel and Fransen 2020). Rural youth who reported that they 'never have quite enough' were the least likely to aspire to stay where they were, whereas rural youth who were involved in agricultural work but were from higher wealth brackets perceived that staying in their locale provided prospects and a viable future (ibid., pp. 22-23). Abebe (2020) described the precarity facing 'educated unemployed' rural youth in the Oromo region, who are unable to access land to continue family farming traditions because of rapid urban expansion. Having also been promised a brighter future as a result of their schooling, they find themselves instead seeking employment in areas such as manual labour. Mains (2012) suggested that this has led to an 'elasticity' of the phase of youth, 
which was previously quite tightly defined chronologically as ending with marriage, home ownership and parenthood-transitions that are not available to youth who are unable to provide for a family.

Significant changes in youth political participation-especially by young, educated men from rural areas-are associated with these shifts in youth transitions. The expansion of educational access in the 1980s and its linkage by the state to a capitalist development strategy that has, in many areas, failed to deliver has politicised Ethiopian youth and drawn them increasingly to political activism (Mains 2012; Abebe 2020). The widespread antigovernment protests in 2017 and 2018 that led to its overthrow had a massive youth turnout, with young people calling for grassroots democracy, regime change and new growth and development strategies (Abebe 2020, p. 596). However, since the election of Prime Minister Abiy Ahmed in 2018, amid great global fanfare, political tensions have continued to erupt nationally in riots and ethnic violence, leading to mass internal displacement. Despite initial government assistance, support for internally displaced persons (IDPs) has dwindled over time, meaning that many IDP youth have been forced to abandon their education to seek work instead (Presler-Marshall et al. 2021). The COVID-19 pandemic has presented the new government with a further crisis. Lockdown measures to curb the spread of the virus have led to a loss of work opportunities and increased food insecurity, exacerbating poverty and the risk of child marriage in rural areas in particular (Jones et al. 2021).

\subsection{Context: Jordan}

In Jordan, the COVID-19 pandemic also met a context shaped by over a decade of political upheaval and protest in which young people have been key actors and organisers, demanding structural change to address government corruption, high youth unemployment and a lack of social safety nets (Ryan 2018). Lenner and Turner (2019) suggested that several decades of neoliberal transformation strategies in Jordan have failed to meet their goals of enhancing private development and investment, with (highly desirable) public sector jobs remaining crucial to the economy. The Arab Spring that began in 2011 helped to stir demands for change among youth in Jordan but also lit the touchpaper on a prolonged civil war in Syria, which led to the forced displacement of millions of people, such that, in 2021, nearly 700,000 Syrian refugees were registered in Jordan (United Nations High Commissioner for Refugees (UNHCR) (2021)). Efforts to create opportunities for 'self-reliance' for Syrian refugees and expand work opportunities for Jordanians through the creation of Special Economic Zones and work permit schemes have been largely unsuccessful. Unemployment among Jordanians has risen continually since the beginning of the Syria crisis, and Syrian refugees experience xenophobia and discrimination in the job market as well as formal restrictions on work (Abid et al. 2017). Accordingly, Sajdi et al. (2021) found that mobility features in adolescents' perceptions of their futures, with many young refugees making plans to leave Jordan in order to seek better opportunities for work.

Youth transitions to work are also deeply gendered, with cultural proscriptions on women's mobility a key factor in their limited employment opportunities (Miles 2002). Prior to 2010, in Jordan, women's job market participation was only 15\%, comparable to the $13 \%$ of women in employment in Syria (International Labour Organization (ILO) (2015)). Limitations on mobility affect women's ability to travel to work or stay late if needed; moreover, it is expected that women will prioritise family responsibilities over paid work (Banihani and Syed 2020). Although women in Jordan are increasingly attaining higher levels of education, this has failed to translate into successful transitions into the labour market, with only one in four young women economically active after completing schooling, compared to $90 \%$ of young men (ILO 2018). Shrinking public sector employment opportunities have disproportionately affected young women's work options, as historically they were able to access higher salaries and better job protection and security through employment in that sector (Miles 2002; Assaad et al. 2020). After school, the 
majority of young women take on responsibilities in the family home such as unpaid care and household work (ILO 2018).

The expectation that girls will comply with the wishes of their family and husband and that their honour and mobility must be safeguarded shapes young women's perceptions of the options available to them. This is particularly the case for refugee girls, who are perceived by their families to require strong protection (Hattar-Pollara 2019). These concerns mean that high rates of child marriage persist among Syrian refugees in Jordan, with some studies finding that the rate has increased threefold compared to pre-displacement ( Abdulrahim et al. 2017). Syrian refugee women in Jordan also have less access to daily and regular work than men due to norms about caring responsibilities in the home and because the types of work available are seen as inappropriate for women (Hanmer et al. 2020). The other side of these norms is lower participation in education by young men; work by Sajdi et al. (2021) found that Syrian refugee adolescent boys have much greater mobility and personal freedom, but as a result, they are often expected to secure work to help their families. Research on the impact of COVID-19 on women and girls in Jordan is already showing that the pandemic and associated lockdowns have resulted in further restrictions on their mobility, as well as a loss of privacy in the home (Małachowska et al. 2020b).

\subsection{State of Research Field}

In both Ethiopia and Jordan, adolescents' trajectories are clearly shaped by mobility, both in terms of the restrictions imposed upon them as a result of gender norms and/or legal status and in that being 'mobile' offers opportunities to transcend these restrictions. Research with young people on the move has documented the intensification of precarity that the COVID-19 pandemic has introduced for those who are already made vulnerable by existing systems that govern mobility (Barn et al. 2021; Couch et al. 2021). In sub-Saharan Africa, research with young migrants engaged in shoe-shining work in Ghana found that youth who lack other opportunities rely on being able to move to access informal work and that the pandemic has had significant negative effects on this livelihood strategy (Dzirasah 2021). Whilst You et al. (2020) underlined that migrant families are less likely to be included in economic recovery plans, which typically exclude informal sectors in which mobile populations are more likely to be working, their analysis did not attend to the experiences of adolescents who work, who in Ethiopia and Jordan are particularly likely to work informally. Driven by the inadequacy of policy responses, research has also found that, particularly in the early days of the pandemic, young migrants and refugees have been active in assisting and responding to the crisis within their communities (Hamad et al. 2020; Couch et al. 2021).

Both the sociology of youth literature and critical migration studies emphasise that mobilities must be understood as functioning within systems designed to maintain the status quo of inequality. Dona and Veale (2011, p. 1273) suggested that humanitarian and social care interventions with migrant and displaced young people happen in a political space characterised by 'divergent or ambivalent discourses'. They identified a tension between children on the move who are made 'visible' through a humanitarian, needs-based lens and those rendered invisible by systems and definitions of mobility, vulnerability or framings of 'children' that fail to account for their lived experiences (Dona and Veale 2011). Critical migration studies, which emphasise the agency and resistance of mobile populations, also provide a counterpoint to depoliticised framings of young people on the move, drawing attention to the mechanisms and governance practices that render certain mobilities legal, acceptable and visible while constraining others (Scheel 2015). In their work on (im)mobilities, for example, Nimfuhr and Sesay (2019, p. 15) drew attention to the 'limbo' experienced by forced migrants who reach European shores, where they must find ways to adapt to social conditions that deprive them of rights and alienate them from support services in order to try and 'navigate a life in between'.

This extant literature affirms the agency of young migrants and refugees who seek out alternatives to danger, poverty or disenfranchisement (even though those alternatives 
are often highly risky and/or likely to confine them to new forms of poverty and disenfranchisement) and who seek to move out of a period of limbo increasingly framed in the literature on youth transitions as 'waithood'. 'Waithood' is defined as a period in which young people are suspended between childhood and adulthood but are actively seeking ways to bridge that transition (Honwana 2012). It is important to emphasise that waithood does not imply passivity; young people actively anticipate and engage with the future from the position they find themselves in (Abebe 2020). However, under neoliberal capitalism and rising global inequality, traditional forms of transition are increasingly unavailable, leaving adolescents 'no longer children in need of care, but ... still unable to become independent adults' (ibid. 28). Mobility has commonly been a strategy for coping with uncertainties; indeed, youth mobilities have been the focus of much of the literature on 'waithood' (Erulkar et al. 2006; Abebe 2020).

With some exceptions, such as Gilbert's (2018) work on a 'feminine culture of waiting' in Nigeria, the gendered nature of 'waithood' has thus far been accorded limited attention in the literature. Some important work, however, highlights how mobility features in young women's strategies for making the transition to adulthood. In her study of Eritrean girls who migrate to Sudan for work, Grabska (2020) drew on the idea of both 'waithood' and 'mobilities' to investigate how gendered identities are shifted by the migration process. She suggested that girls' practices and experiences of waithood differ from those of boys, shaped as they are by the gendered transition to adulthood, which can produce specific 'blockages' in realising one's aspirations. de Regt and Mihret (2020) also observed in their research with adolescent girls who migrate to urban centres and engage in sex work that agency over mobility takes place within highly constrained circumstances shaped by gender ideologies.

Research is already identifying that the COVID-19 pandemic is affecting boys and girls in distinct ways, with implications for their mobility. Prior to the pandemic, adolescents in both Jordan and Ethiopia encountered gendered challenges relating to their mobility and its management-but young men and women also drew on mobility as a strategy to navigate 'waithood' and forge transitions to adulthood. Since the beginning of the pandemic, Jones et al. (2021) found that there has been added pressure upon boys in LMICs to engage in paid work, though they also found that, in Ethiopia specifically, girls too have come under increased pressure to migrate and engage in domestic work during lockdowns and school closures. In Jordan, school closures have prolonged the time that children and young people spend at home, which has created tensions in the household that make girls feel unsafe. The pandemic has broadly resulted in greater restrictions on girls' mobility and increased time spent on household work (Małachowska et al. 2020b). Syrian adolescents in Jordan who were working prior to the pandemic have lost work or had their hours reduced, with young people living in camps the most affected (ibid.).

However, several themes remain inadequately conceptualised in the extant literature. Whilst the impact of the COVID-19 pandemic on boys and girls has been highlighted, there has not been a gender analysis of these effects upon youth transitions. The pandemic has unfolded in the context of existing challenges for mobile populations in Ethiopia and Jordan. Pre-existing inequalities and restrictive gender norms already shaped young people's opportunities and options for mobility prior to COVID-19; it is thus essential that the socioeconomic crisis of the pandemic and related government responses is understood not as an isolated event but as another layer of complexity and disruption to youth transitions. Finally, there has been limited attention to the strategies pursued by young people themselves to navigate 'waithood' under such conditions.

To address these knowledge gaps, this article focuses on migrant and refugee boys' and girls' experiences of the pandemic in relation to three interconnected impacts: first, how young people perceive that gender relations and norms have affected dynamics around mobility at the individual and household level; second, the impact of the pandemic upon opportunities for education and work sought by young people and how they have 
contended with these changes; and last, we look at the gendered impact of these shifts on young people's wellbeing.

\section{Materials and Methods}

This article draws on two rounds of qualitative data collected during the pandemic by the Gender and Adolescence: Global Evidence (GAGE) study which explored the gendered experiences of adolescence and the ways in which adolescent capabilities are either supported or undermined in diverse LMICs, including Ethiopia and Jordan (see Baird et al. 2021). Informed by a socio-ecological conceptual framework, the GAGE study interrogated the interconnectedness of ' $3 \mathrm{Cs}$ ' shaping adolescent experiences: capabilities, change strategies and contexts. Unlike fixed outcome measures, capabilities refer to the ability of adolescents to pursue lives that they value. Attention to contexts means recognising the interplay of social, economic and political factors at family, community and state levels, which can enable or constrain adolescents' opportunities to take advantage of policy and programming interventions. With regards to youth transitions, change strategies may include policies and programming on education, skills building, empowerment and employment that target populations affected by forced displacement and migration-but may also be about the other assets, social norms and resources drawn upon by young people and/or in relation to families and communities.

In this article, the analysis draws on qualitative data to explore how both humanitarian and developmental policy, as well as family, community and other systems, interact to shape adolescents' transitions into early adulthood. Data collection was undertaken in late 2018/early 2019 and the second half of 2020 and included individual and group interviews with adolescents $(n=138)$ and service providers (including teachers, health extension workers and social workers), governmental departments (Women, Children and Youth Affairs, Labour and Social Affairs and Justice), United Nations bodies (UNHCR and UNICEF) and key informants $(n=36)$ (see Table 1 for further details; emboldened numbers in the table denote total numbers of participants).

Table 1. Qualitative research sample for Ethiopia and Jordan.

\begin{tabular}{ccccc}
\hline & Ethiopia & \multicolumn{3}{c}{ Jordan } \\
\hline & $\begin{array}{c}\text { Pre-COVID-19 } \\
\text { 2018/2019 }\end{array}$ & COVID-19 2021 & $\begin{array}{c}\text { Pre-COVID-19 } \\
\mathbf{2 0 1 8 / 2 0 1 9}\end{array}$ & COVID-19 2021 \\
\hline Girls & $\mathbf{3 3}$ & $\mathbf{2 4}$ & $\mathbf{4 5}$ & $\mathbf{2 4}$ \\
Unmarried & 23 & 14 & 31 & 14 \\
Married & 6 & 6 & 6 & 6 \\
With disabilities & 4 & 4 & 6 & 6 \\
Refugee status & $n / a$ & $n / a$ & 35 & 16 \\
\hline Boys & $\mathbf{3 0}$ & $\mathbf{2 4}$ & $\mathbf{3 0}$ & $\mathbf{2 4}$ \\
With disabilities & 4 & 4 & 6 & 6 \\
Refugee status & $n / a$ & $n / a$ & 22 & $\mathbf{1 5}$ \\
\hline Key informants & $\mathbf{1 8}$ & $\mathbf{1 5}$ & $\mathbf{1 8}$ & 4 \\
National level & 4 & 3 & 4 & $n / a$ \\
District level & 6 & 5 & $n / a$ & 11 \\
Community level & 8 & 7 & 14 & \\
\hline
\end{tabular}

The interviews (which ranged from 60 to $120 \mathrm{~min}$ for in-person pre-pandemic interviews and 45 to $60 \mathrm{~min}$ for virtual interviews undertaken following the onset of COVID-19) centred around the perspectives and experiences of young people (aged 15-19 years) and their communities and allowed an in-depth exploration of the multi-layered crises they were experiencing. The interviews followed a methodological toolkit (see Jones et al. 2019; Małachowska et al. 2020a) which was adapted to each regional context and included semistructured interactive tools such as Social Network Hexagon, Worries Exercises and Decent Work Scenarios to explore the quality of young people's relationships within their family 
and community, psychosocial stressors and the types of interventions that are supporting adolescents to transition to early adulthood and opportunities and barriers to decent work. Vignette exercises were used to explore community social cohesion and dynamics, and focus group discussions were conducted to explore the services and programmes that had supported 'significant change' in adolescents' lives. Tools used during the pandemic focused on adolescent experiences of COVID-19-related lockdowns and service closures and the types of informal and formal support that young people were able to draw upon.

Respondents in Ethiopia were from three diverse urban locations: Debre Tabor zonal city (Amhara region), Batu district town (Oromia region) and Dire Dawa city administration. In Jordan, respondents were drawn from refugee camps (Zaatari and Azraq, home to Syrian refugees) and host communities (in Amman, Mafraq and Irbid governorates). Research was undertaken in local languages (Amharic, Afaan Oromo and Somali for Ethiopia and Arabic for Jordan), with respondents being interviewed by researchers of the same sex and from the same regional background as them. Informed consent was sought from those aged over 18 and assent obtained from those aged 15-17; consent was obtained from parents or caregivers except where an adolescent was head of the household. All interviewees were provided with a name card with a project mobile phone contact number, which was checked daily during the fieldwork and periodically between data rounds (young people were encouraged to use it if they had any questions or concerns about the research or as an entry point to report possible violence or abuse). For cases that were reported either via the project phone line or to interviewers in person, a detailed referral protocol was in place whose quality was assured by government and non-governmental experts for appropriateness for each region (given uneven service availability). Ethical clearance for the research was granted by the Overseas Development Institute Ethics Review Board, the relevant Ethiopian regional government ethics committees, UNHCR's National Protection Working Group and Jordan's Ministry of Interior, Department of Statistics and Ministry of Education.

All interviews were audio-recorded, transcribed and translated into English by bilingual transcribers. Data were analysed thematically using a detailed codebook developed in line with GAGE's conceptual framework and, specifically, the psychosocial wellbeing, voice and agency and economic empowerment capability domain sub-indicators (GAGE Consortium 2019) using MAXQDA, a qualitative software package. To ensure trustworthiness of the deductive coding process, a sub-sample of transcripts was double-coded, and weekly debriefings were held with the coding team (research assistants with a qualitative social science background and East African and MENA experience) to discuss issues regarding how to apply the codes in particular geographical and political contexts. Given multiple informants and data collection rounds, we coded each type of respondent separately but then also checked thematic codes to compare and contrast findings within and across country contexts and by gender, migrant and internally displaced person (IDP) or refugee status.

\section{Results}

\subsection{Gender, Mobility and Family}

Despite being older adolescents on the cusp of adulthood, young people in both contexts experience limited decision-making power over how they use their time and their movements in and out of the home due to hierarchical age and gender norms. Our data show that restrictions were often crystallised during the pandemic-related lockdowns. For older adolescent girls in both contexts, mobility constraints during the pandemic were augmented as girls already tended to have very little say over their time use. A 17-year-old girl from Debre Tabor, Ethiopia, explained:

Everyone was worried but males tend to go out and meet with friends whereas females often stay at home to help with chores at home. Females have a higher workload at home than males ... Even if she goes out to work, when she comes home she will still have 
another job to do. She has no break. Males also have jobs but at least they rest when they return home.

For married girls, what little mobility they may have had prior to the pandemic was further eroded following the onset of lockdowns and service closures. As a 17-year-old married Syrian refugee girl living in a host community in Mafraq, Jordan, noted:

Not a lot changed in my life [since the pandemic]. I used to stay home with my daughter and husband. I stay and help my sister-in-law with cooking and I take care of my daughter. I rarely visit people. But now I have not left the house for a month and a half ... I am obliged to stay home and this is not my choice. I cannot even go to the doctor. This annoys me the most.

Many girls also noted that not only was their present wellbeing largely defined by parental demands on their time but also their future opportunities, with pressures to marry to conform to social norms around marriageability and family honour. As a 17-year-old unmarried Syrian refugee girl in a host community in Amman, Jordan, explained:

I have discussed with them [my parents] a lot about not wanting to get married yet, but it is useless. My father tells me "There is nothing left of my life" except to see his daughter safely married. But I am still young and I have not lived my life yet ... However, I am their only daughter ... They do not listen to me-even during the pandemic I am subject to this nagging.

Adolescent boys emphasised the curbs to their personal freedoms that the broader mobility restrictions engendered. For example, a 16-year-old Syrian refugee boy, living in a host community in Mafraq, Jordan, contrasted his relative freedom vis-à-vis parental restrictions pre- and post-COVID-19:

I used to wake up at 7 a.m., go to work and return at 4 pm, have some lunch and rest, and then be allowed to go out with my friends in the evening ... But during the lockdown I was with my family all the time and I felt suffocated. During the partial curfew I feel a bit more relaxed as I can meet some friends ... I spend the night sitting on the roof of the house until morning with other youth, playing cards and drinking tea. I got to know these neighbours during the lockdown.

\subsection{Truncated Education and Work Opportunities}

Truncated opportunities for a better future were emphasised by many respondents. For girls, whose educational futures had often been disrupted by social and economic pressures to marry, this was particularly distressing. As a 20-year-old married young migrant woman from Debre Tabor, Ethiopia, who had been married at 17, explained:

They [my friends] say that wealth is like a dew. If our families had supported our education we could have a good position by now. But because they did not teach us, we are still living as if in a village. And we feel bad about it ... My friends are very sad because of my fate [early marriage]. They say they were expecting me to be working in a good office or to become a judge... When they tell me this, I remember my diligence for my education and the desire I have now for learning and when I compare it with my current situation, I get very upset. I am psychologically tormented when they tell me that.

Of girls who did return after the pandemic-related school closures, many reported that, especially among those in upper primary school or secondary school, a significant number of female classmates had not re-enrolled due to marriage. Some parents had pressured their daughters to marry because of the uncertainty around their educational futures, and others reportedly took advantage of lower levels of surveillance (due to the absence of teachers and health extension workers) at community level of girls at risk of child marriage during the pandemic.

Similarly, a 15-year-old Syrian refugee girl explained that the compounded disadvantage of living in protracted displacement and being denied the opportunity to continue 
their education - in contrast to both Jordanian nationals and their male peers-often has a significant psycho-emotional impact on girls in her community. She gave the example of her close friend who was forced to marry against her will and was experiencing high levels of distress and even suicidal thoughts:

She was 13 years old and was pulled out of school ... She ran away from home as she did not want to get married so young. She begged her family but they were not persuaded ... She sheltered at my friend's house and told us she was thinking to commit suicide. I asked my family to interfere but they [her family] said please do not interfere, she is our daughter... Now she stands by the window and thinks of suicide. She does not leave the house... she has a psychological illness.

Alongside truncated educational trajectories, we find that young people were also facing dwindling opportunities for decent work. It is important to emphasise that prior to the pandemic, many young people in our sample were already experiencing high levels of economic precarity connected to their mobility. For rural-urban migrants, employment opportunities are often highly irregular. As a 19-year-old married girl from Debre Tabor explained, daily labouring work is unstable and does not provide economic security:

In the morning we go to our spot where we wait for people with jobs to approach us. If we get lucky we go to work. If not, we return home and do chores... Daily labourer jobs in construction sites ... it could be anything ... If not I do the chores at the house or help out neighbours with little payment. It is mainly baking injera [traditional flat bread] ... I get 20 to 30 birr [\$0.50 to \$0.70].

Part of the challenge is that migrant workers are often stigmatised because they are outsiders and often from a different ethnic group, with several respondents underscoring that getting salaried employment was all but impossible because of this. A 19-year-old girl who had migrated to Batu town from a rural area of Ethiopia, at age 14, explained her situation:

For the first four years when I came here, I had no work at all. I used to sit and stay at home ... I had competed for a position of janitor. I took the test and was expecting to start the job. But they rejected me, claiming that I am not from here. They hire their own relatives and clan. They also take the bribe to hire someone. So they said we did not give them a bribe and I was not from here.

For adolescent girls, the other main alternative is employment as a domestic worker, but as this falls outside labour law protections in Ethiopia, the risk of economic exploitation is high. As an 18-year-old girl from Batu town noted:

When I came here [from my village] I started working straight away. When working as full-time help, you don't have to worry about house rent. But because you have nowhere to go, the employers will abuse you by giving you lots of work. At one household I worked for one year and six months. I made some savings from working there, I was first hired with 300 birr per month and I knew it was a very small amount because people used to tell me that it is very small. But with no networks and with both my parents having passed away, I had no option.

Some young people explained that they had sought to exchange the precarity of employment with self-employment but that, for young migrants with no start-up capital, this is very challenging and is accompanied by high levels of insecurity. As a 19-year-old girl from Batu, married with children, explained:

I don't have anything, I live in a rented house and I am raising my kids by selling cabbage ...

I used to work for people, baking injera, washing clothes as a daily help. I decided that it would be better for me to do my small business instead of working for other people, and started selling this at the market... I got the money from the saving that I made from working as a daily help. 
In Jordan, the challenges facing refugee youth are even more constrained on account of limitations on what employment sectors refugees are allowed to secure work permits for. Girls face additional restrictions due to conservative gender norms that preclude many girls and young women from seeking employment at all. As a 16-year-old Syrian refugee girl from Zaatari refugee camp in Jordan explained:

My older brother is responsible for household expenses and my mother ... But they are unemployed now. They don't find a job in the camp, although my brother used to work outside the camp but not anymore. He is unemployed... Lack of money affects us, as we are no longer able to meet our basic needs... And for me, no one even entertains the idea that I might work.

Whilst the challenge of economic vulnerability is therefore not new in both contexts, these stresses have been exacerbated by the pandemic and related lockdowns. Many young people noted that employment opportunities had been curtailed. An 18-year-old unmarried Syrian refugee girl in Zaatari camp in Jordan explained that a rare retail job had evaporated once lockdown set in: 'I was not working before the pandemic, but I was planning to work in a store in the market, in a clothes store... But that didn't happen and so I am sitting at home all the time.' Similarly, a 17-year-old married girl in Debre Tabor city, Ethiopia, emphasised that 'It is stressful since corona. I can't work. I feel helpless.' A 15-year-old migrant girl, also from Debre Tabor, noted that her desperation was such that she opted to risk infection rather than see her meagre income dry up completely:

Before COVID, I could at least borrow money from others, but during the pandemic, I didn't even have access to the people who would lend me the money. People were staying at home... Initially I stayed at home but the stress was too intense so I decided to go out and at least work, I said to myself if it [corona] is going to kill, then it should; I can't wait for death here.

Multiple young people also talked about the increasing difficulties they and their families are facing. A 17-year-old Syrian refugee girl living in a host community in Mafraq, Jordan, highlighted that her family was having to compromise on diet diversity as a result of the economic downturn:

Prices of vegetables increased dramatically, the price of a kilo of potatoes become 2 dinars, and the price of a kilo of cucumbers is 2.5 dinars... We used to be able to buy a kilo of vegetables for half a dinar... Fruit we no longer buy since the lockdown.

Similarly, a 17-year-old Syrian refugee boy living in a host community in Mafraq explained that they were having to resort to going into debt and forgoing regular expenses, such as mobile connectivity:

We are living 14 relatives in one house... Three of my brothers used to work before the corona crisis but now there is no work in cafes ... We started to borrow money from relatives. Money goes for food... We used to recharge the credit on our phones but now only one can recharge his credit.

\subsection{Coping with Immobility}

For those who had been in school prior to the pandemic, disrupted education pathways as a result of lockdowns emerged as an important concern in our findings. In part, this is because of the negative impacts on young people's opportunities to interact with their peers. This has in turn led to high levels of distress amongst young people and a sense of hopelessness and frustration about the future. Again, we observe gendered effects, with girls in particular noting that pre-existing constraints on their communications and connectivity exacerbated their sense of social isolation once the pandemic set in. A 17-year-old Syrian refugee girl from a host community in Amman, Jordan, noted:

I have spent more time with my family during the lockdown but the communication and the relationship with them has not improved... And with my friends I have become totally disconnected from them ... I have no communication. Not with school friends. 
Not with neighbours ... rarely I contact them using my dad's phone. Before corona, I used to meet them in the school and see them daily.

These feelings of stress due to disconnection from friends were echoed across contexts and also by boys. For example, a 16-year-old Syrian refugee boy living in a host community in Amman, Jordan, noted that:

We used to go to school every day and see our friends and say hi to them and sit with them, see the teachers, see people and our neighbours. Now, we are alone, we can't see anybody, and nobody can see us, so we feel nostalgia for our relatives, friends and school.

As an 18-year-old girl from Batu town in Ethiopia emphasised:

It is a problem for all people, our world is shaken because of corona. We do not study together, we are told to keep distance. We discuss with friends about education by phone but we do not come close to each other. We are far from friends because of COVID ... We do not shake hands, we keep our distance, we are afraid of corona.

An 18-year-old boy from Batu town, Ethiopia, explained that the loss of social networks was often long-lasting because many migrants were not able to sustain their livelihoods in urban centres and had been compelled to either return to their rural villages or move to other cities in search of work, particularly in the absence of effective social safety nets for urban youth:

I have missed lots of things due to the emergency. Most importantly, I was separated from my friends from school. That's the main thing I've missed. And now I don't have friends as they have moved to other areas in search of work.

Many young people noted that because of the disruption to their social support networks during the pandemic, their already precarious coping skills were stretched almost to breaking point. A 19-year-old adolescent boy, a Jordanian national from Irbid, observed that the stress of the pandemic had been such among his peer group that professional support was called for:

Most people used to like staying at home before, but obligating people to stay at home for extended periods is really hard. I tell myself that I need a psychiatrist after this crisis as there is real and significant stress. We should focus on the social support after the end for people who were subjected to that...

In Ethiopia and Jordan, young people noted that in the context of broader social, economic and political vulnerabilities, close peer networks are often what sustains them, and when this is threatened, it is very challenging. A 19-year-old migrant girl from Batu, Ethiopia, underscored that her coping repertoires were exhausted:

I was not able to do anything [during the state of emergency]. I was not able to think anything and was terrified as everyone talked about the fear of COVID-19. I was not able to think and I used to be like a dead body.

Similarly, an 18-year-old girl from Dire Dawa city, Ethiopia, explained:

It was a very tough time. I don't have words to tell you about that ... People in Dire Dawa have a communal life. We socialise with people very much. It is not like Addis Ababa. So it was very tough for me to stay at home and not to meet others. I cannot go out of the house. I used to stay at home. I didn't want my family to worry about me so I preferred to stay home ... but we are used to hugging each other and showing our concern to each other... I haven't met my friends at all during corona.

For young people with disabilities, the sense of isolation was further compounded. As the mother of a 16-year-old Jordanian boy with a hearing disability in Mafraq observed:

He is very worried about corona. He is very much afraid ... he does not shake hands with anyone and he disinfects his hands all the time. He also washes his body twice a day ... He tells me that it causes death to shake hands ... as the virus can be transmitted 
through touching. He knows better than non-disabled boys ... But he is more anxious than his brothers and sisters. He shouts a lot. He is stressed. He is used to going outside the home...

There were also multiple reports of increased reliance on substances during the pandemic (particularly among boys), mainly smoking (Jordan) and chewing khat and drinking alcohol (Ethiopia). As a 19-year-old boy from Debre Tabor city noted:

When the schools closed, many adolescents were doing nothing. They just isolated themselves hoping that school would reopen again. Some couldn't work as they were under such stress ... and some turned to addictions, like smoking, chewing khat, drinking alcohol.

Several girls noted that boys appeared to be at greater risk of addictive behaviours as they were less likely to talk about their emotions in a crisis situation than girls. As a 19-year-old girl from Batu noted:

When males get angry they might get involved in addictions like drinking, smoking, or chewing khat, which gives them short-term relief, and there are also some females who do the same as a coping mechanism. In my view this would appear to be an absence of listening to one's inner feelings... You need to think critically before taking such actions ... and then you can share with someone. It is helpful to identify the good and bad options to decide about your future.

\section{Discussion}

In both Ethiopia and Jordan, mobility has historically been a source of expanded opportunities for young people who faced an extended 'waithood' due to political and economic changes that have altered what transition to adulthood looks like. In Ethiopia, rural-urban migration usually enables access to job opportunities, while in Jordan, where refugees encounter formal restrictions on their movement, mobility within communities and the social and economic solidarity offers a coping mechanism for the challenges of protracted displacement. Yet the pandemic-induced crisis has arrived amidst ongoing mass displacement and irregular migration, conditions under which young people already encountered social and political immobilities based on their age, gender, disability and citizenship. Under the conditions of the pandemic, these immobilities have become even sharper-with significant consequences for young people's trajectories.

Young people's experiences of the COVID-19 pandemic in Ethiopia and Jordan are not simply characterised by dwindling opportunities for education and work as a result of lockdowns; our findings show that in the context of multi-layered crises, many feel their chances for a better future are rapidly vanishing. Whilst the pandemic has, in many ways, placed everyone into 'waithood' - with schools closed, job opportunities lost and mobility curtailed-for some young people (many of whom are particularly vulnerable), it has accelerated the transition to taking on more responsibilities (Jones et al. 2021). Yet as the findings on adolescent wellbeing show, the movement of boys into waged work and girls' increased orientation towards household duties during the pandemic cannot be considered a successful transition out of 'waithood' when it has been triggered by demands around economic survival and security. Because of their awareness of the importance of their trajectories into early adulthood for their future opportunities, these developments have served to heighten anxieties among adolescent boys and girls about what will happen to them in the long term. Both the availability of opportunities for education and decent work and young people's agency to seek these out are being truncated because of the curtailment of mobility as a result of the pandemic. This risks further exacerbating inequalities in outcomes for girls and boys-especially as marriage largely forecloses girls' future opportunities for schooling and employment.

Furthermore, our findings also suggest that the pandemic has exacerbated the crisis of access to decent work for young people that already characterised both contexts. In rural Ethiopia, adolescents face challenges accessing agriculture-based livelihoods that can 
provide the financial security needed to transition to adulthood. This is a major driver in rural-urban as well as transnational migration-both of which are now much more challenging to pursue. For young migrants in Ethiopia, work opportunities were already limited, with high levels of urban unemployment and a high risk of exploitation-both for girls in domestic work and girls and boys who work as day labourers-alongside scarce opportunities to access credit or become self-employed. In Jordan, truncated labour markets and limited options for refugees to secure formal employment, coupled with gender norm pressures on adolescent girls to avoid movement outside the home, serve to prolong periods of 'waithood'. These vulnerabilities have been exacerbated due to widespread job losses under lockdown measures.

On top of this crisis of work, education feels increasingly out of reach to young people, both due to the need to undertake waged work to help families survive and because of connectivity costs associated with distance learning. The risk here is that young people will either become increasingly 'stuck' in protracted waithood or be forced to pursue routes to adulthood that put them at risk of poorer outcomes in the long term. Particularly significant in our findings are the negative effects on the wellbeing of young people, who report feeling distressed and hopeless. This has hitherto not been explored in the extant work on the pandemic which has stopped at reporting economic and education effects. Not only must young people face a lack of opportunities for improving the future that awaits them, but the social isolation they encounter increases the daily stress of living under the conditions of the pandemic. As shown here, girls and young people with disabilities are particularly vulnerable, as their isolation and lack of peer interaction make these feelings harder to cope with.

Existing literature on migration, gender and youth has emphasized that gender inequality shapes the trajectories of mobile populations. However, conceptualising of adolescence as a period of 'waithood' draws attention to the systemic and political conditions which are amplifying the impact of a crisis of this breadth, unfolding in contexts where mobility is one of the few strategies available to marginalised young people seeking to build a better future. These findings thus underscore the urgent need for youth- and genderresponsive packages of social protection support that explicitly target youth affected by displacement and distress migration. These should include economic support as well as access to market-appropriate skills building and credit. Community-based psychosocial support and opportunities (especially for married and unmarried girls and young women) to interact in safe spaces are also vital for supporting the connections that are being lost through successive lockdowns.

\section{Conclusions}

This article explored how young people in Ethiopia and Jordan affected by mass displacement and distress migration for work are affected by and respond to multi-layered crises induced by the COVID-19 pandemic. The pandemic and its consequences have introduced a further layer of complexity and disruption to youth transitions, not only because they have further narrowed opportunities for successful transitions, but also because they have brought added constraints for young people in seeking alternative pathways to adulthood. Young people in Ethiopia and Jordan who are already 'out of place' have been made even more vulnerable by the pandemic because of its impacts on economic opportunities, service delivery and political stability.

In both contexts, existing inequalities based on gender, age and disability are seen to intersect with (im)mobility to further constrain young people whose movements were already subject to social, political, formal and informal restrictions. The consequences for young people's access to social support networks, education and work are prolonging 'waithood' for some, while others are seeing their transitions accelerate in ways beyond their control. Young people's diminished options to navigate this new crisis risks propelling their trajectories in directions that will have long-term negative consequences for their 
participation beyond the home, opportunities to successfully transition to adulthood and overall wellbeing.

Author Contributions: Conceptualization, N.J. and K.P.; methodology, N.J.; formal analysis, N.J., S.A. and W.Y.; investigation, N.J., W.Y. and S.A.; resources, N.J.; writing-original draft preparation, N.J. and K.P.; writing - review and editing, N.J., K.P., W.Y. and S.A.; supervision, N.J.; funding acquisition, N.J. All authors have read and agreed to the published version of the manuscript.

Funding: This research was funded by UK aid from the UK government.

Institutional Review Board Statement: Ethical clearance for the research was granted by the Overseas Development Institute Ethics Review Board, the relevant Ethiopian regional government ethics committees, UNHCR's National Protection Working Group and Jordan's Ministry of Interior, Department of Statistics and Ministry of Education.

Informed Consent Statement: Informed consent was sought from those aged over 18 and assent obtained from those aged 15-17; consent was obtained from parents or caregivers except where an adolescent was head of the household.

Data Availability Statement: Readers can contact the GAGE programme office at gage@odi.org.uk to apply for data on request for any survey data.

Conflicts of Interest: The authors declare no conflict of interest.

\section{Notes}

1 The national census was last conducted in 2007, and although it was due to be collected in 2017, it has been repeatedly postponed on account of political unrest.

\section{References}

Abdulrahim, Sawsan, Jocelyn DeJong, Rima Mourtada, and Huda Zurayk. 2017. Estimates of early marriage among Syrian refugees in Lebanon in 2016 compared to Syria pre-2011. European Journal of Public Health 27: 323. [CrossRef]

Abebe, Tatek. 2020. Lost futures? Educated youth precarity and protests in the Oromia region, Ethiopia. Children's Geographies 18: 584-600. [CrossRef]

Abid, Raith Zeher, Shakila Abdul Manan, and Zuhair Abdul Rahman. 2017. "A flood of Syrians has slowed to a trickle": The use of metaphors in the representation of Syrian refugees in the online media news reports of host and non-host countries. Discourse $\mathcal{E}$ Communication 11: 121-40. [CrossRef]

Assaad, Ragui, Rana Hendy, Moundir Lassassi, and Shaimaa Yassin. 2020. Explaining the MENA paradox: Rising educational attainment yet stagnant female labor force participation. Demographic Research 43: 817-50. [CrossRef]

Baird, Sarah, Nicola Jones, Bassam Abu Hamad, Maheen Sultan, and Workneh Yadete. 2021. Capturing the complexities of adolescent transitions through a mixed methods longitudinal research design. In Sustainable Human Development across the Life Course: Evidence from Longitudinal Research. Edited by Prerna Banati. Bristol: Bristol University Press.

Banihani, Muntaha, and Jawad Syed. 2020. Gendered work engagement: Qualitative insights from Jordan. The International Journal of Human Resource Management 31: 611-37. [CrossRef]

Barn, Ravinder, Roberta Teresa Di Rosa, and Theano Kallinikaki. 2021. Unaccompanied Minors in Greece and Italy: An Exploration of the Challenges for Social Work Within Tighter Immigration and Resource Constraints in Pandemic Times. Social Sciences 10: 134 [CrossRef]

Camfield, Laura. 2011. "From school to adulthood": Young people's pathways through schooling in urban Ethiopia. European Journal of Development Research 23: 679-94. [CrossRef]

Central Statistical Agency. 2014. Statistical Report on the 2013 Employment Survey of Addis Ababa. Addis Ababa: The Federal Democratic Republic of Ethiopia.

Couch, Jen, Nadina Liddy, and James McDougall. 2021. 'Our Voices Aren't in Lockdown'-Refugee Young People, Challenges, and Innovation During COVID-19. Journal of Applied Youth Studies 4: 239-59. [CrossRef]

de Regt, Marina, and Felegebirhan B. Mihret. 2020. Agency in constrained circumstances: Adolescent migrant sex workers in Addis Ababa, Ethiopia. Journal of Eastern African Studies 14: 512-28. [CrossRef]

Di Nunzio, Marco, and Felegebirhan B. Mihret. 2015. Embracing uncertainty: Young people on the move in Addis Ababa's inner city. In Ethnographies of Uncertainty in Africa: Anthropology, Change and Development. Edited by Elizabeth Cooper and David Pratten. London: Palgrave Macmillan, pp. 149-72.

Dona, Giorgia, and Angela Veale. 2011. Divergent discourses, children and forced migration. Journal of Ethnic and Migration Studies 37: 1273-89. [CrossRef]

Dzirasah, King David. 2021. Migrants' Vulnerabilities and Their Responses to the COVID-19 Pandemic: A Case Study of Mobile Shoe Shine Boys in the Cape Coast Metropolis. Research Square COVID 19 Preprints. Durham: Research Square. [CrossRef] 
Erulkar, Annabel, Tekleab A. Mekbib, Negussie Simie, and Tsehai Gulema. 2006. Migration and vulnerability among adolescents in slum areas of Addis Ababa, Ethiopia. Journal of Youth Studies 9: 361-74. [CrossRef]

GAGE Consortium. 2019. Gender and Adolescence. Why Understanding Adolescent Capabilities, Change Strategies and Contexts Matters, 2nd ed. London: Gender and Adolescence, Global Evidence.

Gilbert, Juliet. 2018. "They're my contacts, not my friends": Reconfiguring affect and aspirations through mobile communication in Nigeria. Ethnos 83: 237-54. [CrossRef]

Grabska, Katarzyna. 2020. "Wasting time": Migratory trajectories of adolescence among Eritrean refugee girls in Khartoum. Critical African Studies 12: 22-36. [CrossRef]

Hamad, Shoroq, Eman Abu Hamra, Riyad Diab, Bassam Abu Hamad, Nicola Jones, and Agnieszka Małachowska. 2020. Listening to young people's voices under COVID-19. In Exploring the Impacts of COVID-19 on Adolescents in the Gaza Strip. Policy Brief. London: Gender and Adolescence, Global Evidence.

Hanmer, Lucia, Eliana Rubiano, Julieth Santamaria, and Diana J. Arango. 2020. How does poverty differ among refugees? Taking a gender lens to the data on Syrian refugees in Jordan. Middle East Development Journal 12: 208-42. [CrossRef]

Hattar-Pollara, M. 2019. Barriers to education of Syrian refugee girls in Jordan: Gender-based threats and challenges. Journal of Nursing Scholarship 51: 241-51. [CrossRef]

Honwana, Alcinda. 2012. The Time of Youth: Work, Social Change and Politics in Africa. Washington, DC: Kumarian Press.

Honwana, Alcinda. 2019. Youth struggles: From the Arab Spring to Black Lives Matter and beyond. African Studies Review 62: 8-21. [CrossRef]

International Labour Organization (ILO). 2015. Access to Work for Syrian Refugees in Jordan: A Discussion Paper on Labour and Refugee Laws and Policies. Beirut: ILO Regional Office for Arab States.

ILO. 2018. Jordan: Young Women's Employment and Empowerment in the Rural Economy. Impact Brief. Amman: ILO and IFAD.

Jones, Nicola, Elizabeth Presler-Marshall, Agnieszka Małachowska, Emma Jones, Jude Sajdi, Kifah Banioweda, Workneh Yadete, Kiya Gezahegne, and Kassahun Tilahun. 2019. Qualitative Research Toolkit: GAGE's Approach to Researching with Adolescents. London: Gender and Adolescence, Global Evidence.

Jones, Nicola, Silvia Guglielmi, Agnieszka Małachowska, Bassam Abu Hamad, Workneh Yadete, Shoroq Abu Hamad, Eman Abu Hamra, Farhana Alam, Sarah Alheiwidi, Taghreed Alabbadi, and et al. 2021. 'Some Got Married, Others Don't Want to Attend School as They Are Involved in Income-Generation': Adolescent Experiences Following COVID-19 Lockdowns in Low-and Middle-Income Countries. London: Gender and Adolescence, Global Evidence.

Kushkush, Isma'il. 2015. Ethiopia, Long Mired in Poverty, Rides an Economic boom. The New York Times. March 3. Available online: www.nytimes.com/2015/03/04/world/africa/ethiopia-an-african-lion-aspires-to-middle-income-by-2025.html (accessed on 23 November 2021).

Lenner, Katharina, and Lewis Turner. 2019. Making refugees work? The politics of integrating Syrian refugees into the labor market in Jordan. Middle East Critique 28: 65-95. [CrossRef]

Mains, Daniel. 2012. Cynicism and hope: Urban youth and relations of power during the 2005 Ethiopian elections. In Contested Power in Ethiopia. Edited by Kjetil Tronvoll and Tobias Hagmann. Boston: Brill, pp. 137-64.

Mains, Daniel. 2015. Youth unemployment, progress and shame in urban Ethiopia. In Anthropologies of Unemployment: New Perspectives on Work and Its Absence. Edited by Jong Bum Kwon and Carrie M. Lane. New York: Cornell University Press, pp. 135-54.

Małachowska, Agnieszka, Nicola Jones, Bassam Abu Hamad, Taghreed Al Abbadi, Wafaa Al Almaireh, Sarah Alheiwidi, Kifah Banioweda, Abreham Iyasu, Yitagesu Gebre, Kiya Gezahegne, and et al. 2020a. GAGE Virtual Research Toolkit: Qualitative Research with Young People on Their COVID-19 Experiences. London: Gender and Adolescence, Global Evidence.

Małachowska, Agnieszka, Taghreed Al Abbadi, Wafaa Al Amaireh, Kifah Banioweda, Sarah Al Heiwidi, and Nicola Jones. 2020b. Exploring the Impacts of COVID-19 on Adolescents in Jordan's Refugee Camps and Host Communities. London: Gender and Adolescence, Global Evidence.

Miles, Rebecca. 2002. Employment and unemployment in Jordan: The importance of the gender system. World Development 30: 413-27. [CrossRef]

Nimfuhr, Sarah, and Buba Sesay. 2019. Lost in limbo? Navigating (im)mobilities and practices of appropriation of non-deportable refugees in the Mediterranean area. Comparative Migration Studies 7: 1-19. [CrossRef]

Presler-Marshall, Elizabeth, Rebecca Dutton, Nicola Jones, Sarah Baird, Tassew Woldehanna, Workneh Yadete, Tsinu Amdeselassie, Guday Emirie, Yitagesu Gebreyehu, Kiya Gezahegne, and et al. 2021. We Suffer to Survive': Exploring Adolescent Opportunities and Challenges in Securing Decent Work and the Foundations for Economic Empowerment in Ethiopia. Report. London: Gender and Adolescence, Global Evidence.

Ryan, Curtis. 2018. Jordan and the Arab Uprisings: Regime Survival and Politics beyond the State. New York: Columbia University Press.

Sajdi, Jude, Aida Essaid, Clara Miralles Vila, Hala Abu Taleb, Abu Majed Azzam, and Agnieszka Małachowska. 2021. 'I Dream of Going Home': Gendered Experiences of Adolescent Syrian Refugees in Jordan's Azraq Camp. European Journal of Development Research. Available online: https:/ / ezproxy-prd.bodleian.ox.ac.uk:2102/10.1057/s41287-021-00450-9 (accessed on 23 November 2021).

Scheel, S. 2015. Rethinking the concept of autonomy of migration? Yes please! Movements: Journal for Critical Migration and Border Regime Studies 1: 1-5. 
Schewel, Kerilyn, and Sonja Fransen. 2018. Formal education and migration aspirations in Ethiopia. Population and Development Review 44: 555-87. [CrossRef]

Schewel, Kerilyn, and Sonja Fransen. 2020. Who Aspires to Stay? Immobility Aspirations among Youth in Ethiopia, India, Peru, and Vietnam. IMI Working Papers, No. 161. MADE Project Paper No. 12. Amsterdam: International Migration Institute.

United Nations Education, Scientific and Culture Office (UNESCO). 2021. Data for the Sustainable Development Goals. Available online: http:/ / uis.unesco.org/ (accessed on 23 November 2021).

United Nations High Commissioner for Refugees (UNHCR). 2021. Operational Portal: Refugee Situations. Syria Regional Refugee Response. Available online: https://data2.unhcr.org/en/situations/syria/location/36 (accessed on 23 November 2021).

United Nations (UN). 2014. Millennium Development Goals Report 2014: Ethiopia; New York: United Nations. Available online: www.et.undp.org/content/ethiopia/en/home/library/mdg/EthiopiaMDG2014.html (accessed on 23 November 2021).

Wellbeing and Illbeing Dynamics in Ethiopia (WIDE). 2016. Wellbeing and Ill-Being Dynamics in Ethiopia. Discussion Brief. Available online: www.welldev.org.uk (accessed on 23 November 2021).

You, Danzhen, Naomi Lindt, Rose Allen, Claus Hansen, Jan Beise, and Saskia Blume. 2020. Migrant and displaced children in the age of COVID-19: How the pandemic is impacting them and what can we do to help. Migration Policy Practice 10: 32-39. 